\title{
LIFE AND THE SOUL.
}

BIOLOGISTS are agreed that the basic problem of B their science is not yet mature for solution. The origin of life is a mystery still shrouded in darkness by a lack of the necessary data which would throw light on the most primitive conditions of life. But while as yet the details of the problem have resisted scientific inquiry, the problem itself, or let me say the philosophical background of the problem, is by no means so hopeless as is commonly assumed. We know enough of life to anticipate the nature of the explanation of its riddles, and there is not the slightest reason to regard the problem as an unfathomable mystery, an enigma that under all circumstances would defy comprehension.

The problem of the origin of life has been classed by $\mathrm{Du}$ Bois-Reymond among the seven enigmas of the world ${ }^{1}$ and, not without a touch of a love of mysticism, he actually deems the nature of life to be intrinsically unknowable.

In the same way Mr. Spencer and his followers look upon the problem of life as unsolvable, but in both cases we have to deal with a certain philosophical dogmatism which has no foundation. There is a great difference between the unsolvability of a problem on account of subjective and of objective reasons. It is our fault if we do not know enough, and the fault can be remedied. The lacking data can be supplied. But if the obscurity of the

${ }^{1}$ Die sieben Welträtsel. 
subject were inherent in the facts themselves, no amount of science or inquiry would avail.

We doubt whether we have a right to regard as genuine and legitimate those problems which are per se unsolvable, and prefer to characterize them either as illegitimate or futile problems. ${ }^{2}$ Illegitimate problems are wrong formulations, and futile problems are those that ought to be formulated as statements of fact. $^{3}$ For instance the ontological problem "why is reality real?" or "why does existence exist?" ought to be rendered "what do we understand by reality?" The question of the origin of life is one of the most difficult problems with which science is confronted, and there is little hope of solving it at present on account of its detailed complications. Yet, while we recognize the practical difficulties under present conditions with the means at our command, we deem the problem by no means unsolvable or beyond the grasp of man's reason.

The philosophical problem of the origin of life does not investigate the field of physiological details but limits its inquiry to the main outlines of a solution. It attempts to bring clearness into the chaos of riddles by pointing out the direction in which the answer of the main question must be sought. Above all we must learn to distinguish between two factors, (I) the indispensable elements from which life rises, and (2) the conditions which actually cause it to appear. The former must be assumed to be immanent qualities of existence, the latter come to pass by a favorable combination of circumstances.

THE NEW VITALISM.

It may be considered as an established fact that life is a function, not an entity nor a substance. The idea that

'Comp. Fundamental Problems, p. 283 ff.

- Comp. Kant and Spencer, p. 52. 
it might be an entity has long been given up, yet the theory that it requires a special life-substance different from other material is still ventilated now and then. This theory is called vitalism and it is too natural an error to be abandoned entirely without at least making the attempt to adapt it to our modern knowledge.

Vitalism in its cruder or primitive form has been surrendered but it is established in a new sense by Bunge, a prominent Swiss biologist. He claims that life is an energy which is as distinct from all other energies as electricity is different from motion or heat, and it seems to us that in this he is right. Sometimes naturalists are carried too far by their enthusiastic zeal to unify all the phenomena of nature and classify them under one head (which in itself is quite legitimate) and insist upon identifying things which are different. The process of life is certainly sufficiently different from other kinds of energy to be regarded as a type of its own. We need not for that reason declare that it is a supernatural phenomenon, or even that it is per se mysterious, but we may very well bear in mind that it is a phenomenon sui generis which can not be identified either with mechanical motion nor with chemical activity nor electrical phenomena. It is a more complicated process than these three and produces effects which can not be traced in any of the others, and so in my opinion we are perfectly justified in saying that vitality or the function of life is a kind of energy of its own. In this sense we may retain the old idea of vitalism in a modernized form, and classify life by itself.

The conditions of life constitute a department of their own; they are not purely mechanical, nor purely chemical, nor purely electrical. Some processes are mechanical, e. g., the movement of the bones; others are chemical, e. g., the modifications of food stuffs under the influence of saliva; and that electrical phenomena accompany vital 
processes has been proved first by Du Bois-Reymond and lately again by Augustus Waller. Yet the properly vital processes are more complicated than any physical phenomena and accomplish things which are impossible by means of organic chemistry. The vitality of living organisms is not a peculiar substance, but a new complication of processes which justifies us in attributing to it a domain of its own which is pretty well marked off from the rest of nature.

The new vitalism, at least as we understand it, must not be interpreted as an attempt at reestablishing dualism, for life remains a natural phenomenon as much as other forms of energy, be it the lightning in the sky, or the falling stone, or the wonderful display of colors in a reflected beam of light. We would say then that the function of life is a manifestation of energy which forms a category of its own. It is as different from physical processes as chemical combinations are different from purely mechanical movements, - or even more so.

\section{METABOLISM.}

Living bodies consist of the very same materials of which the rest of the world is composed. Chemistry has resolved matter into some seventy chemical elements, and the elements of organic chemistry are absolutely the same as those of inorganic chemistry. Some of the most unstable and lightest elements play the most important part in the function of life, for we may say that oxygen, hydrogen, nitrogen and carbon are the most essential factors in building up living organisms.

Our own bodies are composed of a certain number of chemical elements, a part of which is being constantly spent, and the sustenance of life depends uporı an uninterrupted supply of new material which is furnished partly in the shape of food and partly through breathing. 
The constant change of matter that constitutes the vital process is called metabolism, although the German word Stoffwechsel is much more expressive than the Greek term. Metabolism exhibits two phases, first the building up of life structures, which is called anabolism, and then their partial break-down, which is called katabolism. Anabolism is accomplished by nutrition which is a transformation and assimilation of food; its result is a storage of energy. Katabolism is produced by spending the energy which is followed by a state of fatigue, i. e., an exhaustion which requires the restoration of the impaired structure.

So far as I know, the best investigations on this subject have been made by Prof. Ewald Hering of Leipsic, who is mainly concerned with the physiology of vision, but his theory has a general application, and our present purpose will be best served by quoting a recapitulation of his work from the Encyclopaedia Brittanica, s. v. "Physiology," Vol. XIX, p. 22.

"If the ingenious speculations of Hering, that specific color-sensations are due to the relation of assimilation (anabolism) to dissimilation (katabolism) of protoplasmic visual substances in the retina or in the brain, should finally pass from the condition of speculation to that of demonstrated truth, we should be brought face to face with the fact that the mere act of building up or the mere act of breaking down affects the condition of protoplasm in other ways than the one which we have hitherto considered, viz., that the building up provides energy to be set free and the breaking down lets the energy forth. In Hering's conception the mere condition of the protoplasm, whether it is largely built up or largely broken down, produces effects which result in a particular state of consciousness. Now, whatever views we may take of consciousness, we must suppose that an affection of consciousness is dependent on a change in some material. But in the case of color-sensa- 
tions that material cannot be the visual substance itself, but some other substance. That is to say, according to Hering's views, the mere condition of the visual substance as distinct from a change in that condition determines the changes in the other substance which is the basis of consciousness. So that, if Hering's conception be a true one (and the arguments in favor of it, if not wholly conclusive, are at least serious), we are led to entertain the idea that, in addition to the rough propagation of explosive decompositions, there are continually passing from protoplasm to protoplasm delicate touches compared with which the nervous impulses which with such difficulty the galvanometer makes known to us are gross and coarse shocks. And it is at least possible, if not probable (indeed present investigations seem rapidly tending in this direction), that an extension of Hering's view, with such modifications as future inquiry may render necessary, to other processes than visual sensations, more especially to the inner working of the central nervous system, may not only carry us a long way on towards understanding inhibition and spontaneous activity but may lay the foundation of a new molecular physiology. This, however, is speculative and dangerous ground. But it seemed desirable to touch upon it since it illustrates a possible or probable new departure. What we have said of it and of the more manageable molecular problems of physiology will perhaps show that, vast and intricate as is the maze before the physiologist of to-day, he has in his hand a clue which promises, at least, to lead him far on through it."

We do not mean to enter here into the details of the physiological problem. We wish to set forth the philosophical aspect of the question alone, and so we need only the most general data of the physiology of life, and for our purpose it is best to limit our views to the physiology of animal life. 


\section{ANIMAL LIFE AND CONSCIOUSNESS.}

It is not impossible that animal life is the simpler and more typical, perhaps even the more primitive form of life, and that plant life is of later origin. The differentiation may have occurred when in some cases the katabolic state was abandoned. It is possible that the most primitive organisms are simply metabolic structures, building up and breaking down. The preponderance of either katabolism or anabolism could easily lead to a differentiation. Plants are purely anabolic, while animals are prominently katabolic; and the more they develop their animal nature the more dependent do they become on the anabolism of plants.

Both domains, animals and plants, form a unity. Plant life seems stunted without animal life. It consists in a constant storage of energy waiting for the animal to utilize it, while animal life as we know it can not exist without plant life.

There is another contrast: An animal is, as it were, a plant that has its roots within itself, and a plant is like an animal whose stomach lies outside. This fundamental difference has an important consequence. Plants are stationary, while animals drift about. Plants are limited to the food that is conveyed to them. Animals must seize their nutriment and introduce it into their system, which forces them to go and hunt their food. But this very inconvenience offers them wide possibilities of a further education.

There are some animals which are stationary, such as corals and oysters. They have become fixed in their places by peculiar conditions and their food is carried to them by the surge that is in constant motion. Since we do not mean to enter into the physiological side of the problem, there is no need of discussing this exception which is apparent only and has practically nothing to do with our present problem. 
The most important implication in the difference between plants and animals resulting from motility, is the rise of sentiency. In a limited degree plants, too, are sensitive or rather they possess a germ of sensitiveness which is called irritability. Irritability is a feature of all living matter, but in plant life it is limited. On a special irritation, i. e., an impression received from the outside, a certain movement is set free and this process is called reaction. The leaves of the sensitive plant when touched fold upon one another, and the Venus's fly trap will close its lid if a fly enters the calyx. We need not discuss here the finer differences between the irritability in the vegetable world and the sensibility of animal life. Be it sufficient to point out that both animals and plants are possessed of irritability, but that irritability appears in a more highly developed form in animals as sensibility. The main difference is that the irritability of plants remains purely physiological while in animals it develops into psychical states.

Here we touch the most significant feature of existence. In animals sensibility is possessed of an element which in the long course of evolution finally appears in the lower animals as feeling, and in the higher animals, especially in mammals, as consciousness, and in man as self-consciousness.

The appearance of consciousness has been the most puzzling problem of science, and it may be deemed the most difficult complication of the problem of life.

\section{LIFE A PRODUCT OF ORGANIZATION.}

The present number of The Monist contains two articles on the problem of life, one by Professor Arrhenius, well known for the distinction of having received the Nobel prize, and the other by J. Butler Burke, who has made a specialty of the problem of life. We have our own views on the subject, but are glad to present their solutions in 
order to show how men of thought deal with this difficulty, and what propositions they have to make.

It is interesting to learn that so great an authority as Professor Arrhenius deems a transportation of life-germs possible not only from planet to planet, but also from one solar system to another, and so he makes our souls thrill at the idea of a possible kinship of our own life with that of the whole universe. He calls his theory "panspermy," and though it can never be proved, we may grant its possibility. Whether true or not the problem as to the origin of life remains, for if the life of our own planet is due to some germs that have been wafted hither from other worlds the problem remains the same. Those germs must have originated somehow, and if not, shall we consider them as consisting of a substance of their own? Shall we fall back on the old theory of vitalism? This is not Professor Arrhenius's meaning, apparently, for he does not deny that life-germs may also have originated independently on our own planet, and he assumes that the germs of our own planet would be very much like those of extra-terrestrial origin.

Mr. Burke's theory is radically different from that of Professor Arrhenius, and we ought to add, much bolder. He assumes that atoms are not absolutely like one another, an assumption which we may grant as possible, but if there are differences they must be trifling, for scientists are unable to trace them anywhere. We must consider that results produced by actions of masses the constituents of which are counted in numbers in which billions and trillions are negligible quantities, ought either to show irregularities in a marked degree or (if they are rare exceptions) would disappear. Now, so far as our minutest observations have gone, it appears that any molecules of elements can replace any other molecules of the same kind and number, without altering the result; and it would not 
be impossible that the ultimate elements of matter of any kind are for all practical purposes absolutely equal. They may be formed with mathematical exactness and may be as true and as perfect in their shape as the light waves of the ether seem to be uniform.

Mr. Burke builds upon his assumption of the irregularity of atoms a new theory of the origin of the variety of different creatures endowed with life.

But the differences in animal organisms, and further in the characters of men, are not founded upon a difference of substance, as Mr. Burke would assume, and can much more easily be explained by a difference in the grouping of the elements of the animated life-cells and by their specialization into different functions. It is not a difference of matter but of form. The villain is made of the same material as the genius. There is no essential difference in their bodily structure, and if we could analyze their brains in an entirely reliable and absolutely perfect chemist's retort, we should not expect to find the slightest difference. Character, as we know, is a matter of form, and the difference implies a difference of activity and also a difference in the direction of activity. No one as yet has tried to discover a material substratum for a difference of direction, for that is due to form and is conditioned by relational circumstances. We might as well try to explain the excellence of Raphael's Sistine Madonna by the peculiarities of the canvas on which it is painted. The same is true in all difference in character, not only between different persons but also between the human and animal organization, and in organized life in general. The animal lifesubstance which, as chemists teach us, is approximately the same everywhere, will not yield to us the secret of the origin of life, for life is not a matter of substance, nor even of energy, but simply a question of form.

The seat of our intellectual life is generally granted 
to be in the brain, and we know that the brain consists of most unstable structures which are subject to a change of material with every act of thinking. How then can we expect that the most essential differences of soul depend upon the peculiarities of some atoms? Suppose, however, this were true, what peculiar complications would arise, what new problems, theoretical as well as practical, and how important it would be to discover the most valuable atoms and to incorporate them into our system! Or shall we assume that there is a central atom somewhere in the brain which is not discarded in the general flux of matter and constitutes our personality?

The difference between living and inert substance, as we learn from its most obvious features, is due to organization. We might as well call living substance organized substance and inert matter that which is not organized. The terms "living" and "organized" are synonyms, and chemistry actually makes this distinction when speaking of inorganic and organic chemistry.

We must, accordingly, next discuss the question "What is organization?"

\section{THE PRESERVATION OF FORM.}

The function of organization (as we have stated above) is metabolism, but there is one peculiar feature in metabolism which must not be overlooked, because it is the essential condition of all higher development. This is the preservation of form, and the question now rises, How can the form be preserved of a substance which is confessedly in a constant flux?

The answer is simple enough. Living substance is neither a liquid nor a solid, but a form between the two which is a state of aggregation that is called viscous. $V$ iscosity affords sufficient stability to retain sameness of form in a change of substance, and we must assume that in 
the normal metabolism every breakdown or katabolic act is succeeded by an act of anabolism which reconstructs the original form. The breakdown is not entire but only partial. Though all living substance is very unstable, there are portions which are more so than others and to these the breakdown is limited. There the oxygen combines with carbon into carbonic acid, which is discarded as waste. Other elements are more or less implicated. They pass out of the system and in the process of restoration their places are filled up again by elements of the same kind in the very same configuration as their predecessors. We have only to assume that the atoms of organized structures possess a dearth of, or an affinity for, those atoms which break away in the katabolic process. They are thus attracted to their respective places and the result is the renewal of the former configuration.

Biology has investigated the lowest forms of life, such as microbes, fungi, and bacilli, and we see that everywhere life is the product of former life. We have not yet reached the lowest limit of life-forms. The very lowest fungi are already highly complicated, simple though they may appear in comparison to any of the higher animals. They are already the product of a definite heredity, that is to say, of a preservation of definite life-forms. Every kind of bacillus has its own type, and is produced only by spores of its species. We have not yet discovered the simplest forms of life-organisms. In the meantime naturalists have tried by artificial means to produce in the chemist's retort some living substance. They have succeeded in producing organic matter, the first substance thus secured being urea, but they have not succeeded in building up an organism, and there is scarcely any hope for success in producing the smallest living bacterium. This repeated failure has caused mystics to claim emphatically that life is a mystery that can never be solved, but in fact it only 
proves that the original life-forms are too small to come as yet under our notice. If we only consider that the smallest fungi are about as complicated in comparison to atoms, as a tree is in comparison to a cell, we will understand that we need better microscopes than are now at our disposal before we can discover the most primitive form of life.

Theoretically considered it should not be impossible to reproduce organized life. The tendency of certain elements to organize into life plasm is in itself no more mysterious than chemical affinities or the formation of crystals.

There is no consistency in the methods of those who see nothing extraordinary in purely physical processes but are overawed when contemplating the basic fact of all biological phenomena, the formation of living structures. There is no less reason why the simplest life-forms under favorable conditions should not organize certain elements into the structure of life-organisms than for vapor to assume the form of snow crystals in the air at a given temperature, and neither process is theoretically incomprehensible. Both are equally mysterious and equally possible.

The difficulty in reproducing the smallest organism at all is due to the fact that all organisms known to us are already the result of a long development. Every one of them possesses a structure of its own which is the product of former impressions, the traces of which have been preserved and constitute its idiosyncracy, i. e., its definite character. In order to produce the simplest fungus we would have to repeat in our laboratory all the processes which this species has passed through, from its origin as a speck of life until it became so specialized as to be a fungus with all its mysterious qualities and endowed with a distinctive character of its own. This may mean a development of millenniums or even more. 
Consider then what the formation of a homunculus would imply. It would mean to repeat all the sense impressions that have formed all those numberless structures by artificial means, and the probability is that the natural process would be the quickest way of doing it. We would need for the experiment a planet in its primordial state soon after the formation of its crust, and must then allow a primitive speck of life to pass through the same process as did man from his primeval origin. We grant that the process might be abbreviated, but even then it would take too long to be actually attempted and so nature's way would after all prove the easiest way of producing the homunculus.

Those who are enthusiastic about producing life by artificial means forget the rôle which the preservation of form plays in the development of definite life-structures. So far we have been able to bring under observation only creatures whose character has been sufficiently specialized through a long period of development to make them unquestionably organic in their structure. Our microscopes are not powerful enough by far to show us the interaction even of molecules, much less of atoms. We even do not know whether atoms are discrete bodies of definite outline with a distinct individuality, or whether they are simply a mode of calculating the proportions in which the different elements combine. Until the time of the invention of microscopes that can look into the atomic structure of organisms we are not likely to discover the conditions under which organized life has originated and could be artificially reproduced. But while the origin of life is hidden from our observation there is no reason to assume that it is an unsolvable mystery, for we know positively that the nature of living substance is conditioned by organization, and organization again is a matter of form. 


\section{THE SPONTANEITY OF LIVING SUBSTANCE.}

The problem has been raised, how can life which is possessed of the faculty of self-motion originate from a world of inert matter? But a closer inspection of the nature of matter will show that even the inorganic elements are not devoid of self-motion. The chemical atoms combine with or separate from other atoms according to definite affinities, and we have no reason to believe that their action is due to push. At any rate the assumption of a vis a tergo would be of no help to solve the problem of motion in the world, for it would only place the source of energy further back and would make that substance from which this pressure proceeded the really automatous or self-moving element. There is an activity even in so-called inert matter commonly named gravity, and there is also activity in chemical action. So we might as well consider self-motion an inherent quality of all substance as to credit it to some mysterious medium such as the ether which (for some good reasons) is assumed to surround and permeate the world of gross matter.

With respect to automatous motion organized life is by no means different from inorganic nature. Both move and are moved, there is attraction and repulsion; and if we analyze the nature of attraction and repulsion in the domain of animal life we find that life is possessed of the same kind of energy that is found in the domain of inorganic matter. Energy is simply motion, i. e., change of place; or strain, i. e., the possibility of producing motion. Energy, whether vital or purely physical, is measurable in foot pounds, and considered as energy pure and simple there is not the slightest difference between the two. Accordingly it is not motion nor self-motion which is the typical quality of organized life, but it is that function of the preservation of form which is due to organization, and 
which in the animal world becomes the basis of the development of soul.

So far we have come to the conclusion that all existence is possessed of energy, which means it is automatous or bears in itself the power of spontaneous motion. We do not say that this spontaneity is arbitrary or haphazard, but on the contrary we conceive it to respond to stimuli in a definite way according to conditions most rigorously determined by laws of form. This spontaneity common to all existence attains a higher plane of chances with unlimited possibilities through organization. Organization intertwines the action of smaller centers by cooperation into larger and larger groups so as to produce higher and ever higher units of efficiency. There is a certain cooperation also in the physical and chemical world, but the cooperation of organized animal life (as we can infer from its effects) possesses one peculiarity of which inorganic nature seems to be absolutely void. It establishes an interrelation of the inner or subjective aspect of existence and so produces a concentration of its most intimate feature, the in-itself-ness of things.

What this inner aspect of things is can be inferred from its final result in organized animal substances: it is the awareness of their own being, viz., feeling, consciousness, psychic states, implying pain, pleasure and cognition.

THE INNER ASPECT OR SUBJECTIVITY.

The appearance of feeling is sometimes regarded as the greatest riddle of life and so it is. Nevertheless, we claim that whatever may be the practical difficulties of comprehending the several physiological conditions necessary for the rise of sentient organisms, the philosophical problem is not beyond any possibility of solution. We have but to assume that just as energy is a universal prop- 
erty of all substances so that quality which is the condition of sentiency must be in existence everywhere.

We conceive of all existence as being like ourselves possessed of two aspects. It manifests itself objectively as action and subjectively as feeling. Within ourselves we are sentient beings, but externally in our relation to other existences we appear as bodies moving about, reacting upon our surroundings.

We call the innerness of existence "subjectivity" and the outerness "objectivity," and we regard both as aspects looked at from two different points of view. Every process in life can be looked at from two sides, either from within or from without. We ourselves call the innerness of our being our soul, and the outerness our body. In ourselves we feel our existence as awareness or consciousness, or in a word, as soul. The word soul most likely means the innerness of things. The German word Seele is still used in other applications as the inner portion of things. In the terminology of artillery the hollow inside of the cannon is called Seele, and Federseele is the pulp that is found inside of a feather.

Now I do not mean to say that atoms or molecules have souls or that they are endowed with intelligence-that theory, which is called panpsychism, ${ }^{4}$ is a mistake,- $-\mathrm{I}$ only claim that every atom (or generally speaking all existence) possesses that subjectivity or innerness, a mere potentiality of feeling, out of which through organization the soul is woven.

Now we note that in the course of evolution which starts with the formation of organized substance, the significance of this innerness or subjectivity grows until it reaches the height of self-consciousness which is a characteristic of the rational soul of man. We must assume, therefore, that the

- For a discussion of panpsychism with Mr. Thomas A. Edison and Prof. Ernst Haeckel see The Monist, III, $234 \mathrm{fi}$. 
interconnection of atoms and molecules in animal organized substance is such as to favor a cooperation of the subjective elements, while all inorganic combination leaves their inner potentialities still isolated.

The most simple state of consciousness is called a feeling, but we know very well that every feeling is already a highly complicated state of subjective awareness which presupposes a number of minor states of the same kind but more feeble, more insignificant, and less intense. The intensity of a clear and well defined feeling is due to the cooperation of a great number of minor subjective states which are called subliminal feelings because they fall below the threshold of consciousness.

When considering how infinitesimal the sentiency of a fly must be in comparison to the subliminal feelings of a human organism, and again, how much smaller still the sentiency must be of the several tiny cells of which the vital parts of the fly consist, we may approximately realize the absolute dimness of the feeling which stirs the innerness of the most primitive organized substance.

Here, if anywhere, in these minute specks of life-substance, we have a semblance of the mathematical idea of an infinitely small quantity; and yet it is only a semblance of it, for these most primitive structures must be discrete and real bodies which, if they could but become visible in microscopes of enormous power, would reveal a definite shape with a definite interrelation of parts and operating in a definite way. From such a primitive interlinking of subjectivities, the life of the soul has sprung; and we explain the origin of actual feeling out of the potential feeling of subjectivity from the consideration that isolated subjectivities remain blank; they become real feelings only by the cooperation with other potential feelings. Isolated feelings are mere irritability and feelings of any kind, potential as well as subliminal, can become states of aware- 
ness only by being felt, and further one feeling can be felt by another only when internally interconnected through organization.

We are inclined to think that the subjective stir which develops into feeling takes place in the process of metabolism. It is a complicated process of oxidation or slow burning and it has been specialized for the function of sentiency in nervous substance, especially the gray matter of the brain.

So far as we can judge, the inner or subjective aspect of existence remains without any significance in the inorganic world, for there the actions or reactions of all things take place according to their external shape only. They have no choice; they act without previous deliberation. Their actions depend solely on their own constitution and the impacts of surrounding conditions. Ideas, thoughts, purposes, are utterly foreign to them. Gravity is determined by mass, chemical affinity must depend upon atomic structure, presumably the axes of rotation, etc. However, in the life of animals the inner aspect is increasingly gaining in significance. While the psychology of atoms (if we may be allowed to use this expression) would possess no significance whatever, the significance of the inner life (of the soul) grows in importance the higher life rises in the onward march of evolution.

MEMORY.

The most significant feature of the function of life (called metabolism) we have recognized to be the preservation of form; the basic condition of all psychical life of animal substance we find to be memory; and these two, the preservation of form and memory are two different aspects of one and the same thing. Memory is the feeling that accompanies the revival of a trace made by a former impression and so we understand that memory (the resus- 
citability of feeling) is absolutely dependent upon the preservation of physiological structures.

Organization is a correlation which in animal life renders possible a communion of the subjective innerness of its correlated parts. This means that potential feelings are so interrelated as to produce a common effect; they focus, as it were, several subjectivities into one unified state; they intensify them by concentration, which if strong enough reaches the threshold of actual feeling. But the process can not be one of concentration only. Judging from analogy and trying to explain the lower as yet unknown strata of feeling from the higher ones that lie within the range of consciousness, we assume that contrast and comparison play a most important part in the development of the elementary forms of sentiency also. A feeling or state of awareness is lost unless it be connected with other states of feeling, and especially with memories of the past. In other words feeling in order to be felt must be in communication not only with simultaneous but also with prior feelings. Feeling in order to become a real psychic state can not remain isolated but must be organically interlinked with co-existing as well as pre-existing feeling, and this is possible only through memory.

We know that our feelings are different, and we assume that the difference of feelings is due to a difference of form. The nature of a feeling depends upon the physiological function of which it is the subjective aspect, and the function being a reaction upon an irritation depends upon the structure of the sentient organ and the impression or commotion by which it is caused. The reactions that take place in sentient substance leave traces, and if these traces are somehow stimulated their sentiency is reawakened and thereby a feeling is produced which resembles the former feeling in kind. It reproduces it according to the trace it has left in the living substance, and this reproduction of 
former feelings is called reminiscence, and reminiscences are rendered possible through memory, which (we repeat) is the psychical aspect of the preservation of form in living structures. The preservation of form is therefore to be considered as the factor that builds up the soul.

States of feeling, however, are not yet mental phenomena. The most primitive feelings are mere irritations indicating pain or pleasure or indefinite states of various forms. Feelings change into mental states through becoming representative, and this process originates naturally and necessarily in sentient substance under the influence of the surrounding world.

\section{MEANING AND SOUL.}

Suppose we have some simple animal structure,- -say an ameboid speck of life-substance. It is already highly organized and of a complicated formation in comparison to the most primitive life structures, but it is mere raw material in the eyes of the zoologist. This speck of life is subject to constant impacts of the surrounding world, and we know from the sundry facts which illustrate the doctrine of evolution that certain parts of the organism become specialized for special purposes. Ocelli originate first as spots sensitive to light; the organs of smell and taste originate under chemical influence; the ear, which is first an organ of equilibrium containing the otoliths, responds to sound-waves, etc. Every sensation of the sense organs responds to a definite impression and leaves a trace made on a track of a definite form. When an impression of some kind is made, the irritation travels on the tracks into which it fits to the old traces built up by former impressions and reawakens them. This reawakening is felt as a reminiscence, which by implication means that an impact of the same kind as formerly is being made. In this way sensations acquire meaning, they become rep- 
resentative, and external impacts come to signify the presence of external causes.

In the course of evolution the representativeness of sense impressions assumes a clearness which makes possible a conception of the actions that take place in the surrounding world. In other words the things surrounding an organism become more and more represented in analogous forms of feeling. The mind of a creature is nothing but the sum total of and the interaction among all these feelings.

We sum up the case thus: Feelings develop into sentient symbols and the soul is a system of sentient symbols.

This definition of the soul looks very simple but it is of far-reaching consequence. The representativeness of our ideas renders it possible for us to adjust our actions to conditions. It makes possible a conception of the world in which we live. Our soul is comparable to a map of our surroundings in which we know ourselves to be drifting; and since we have definite needs, definite wants, and definite demands, our ideas of things serve us as a guide for our conduct. In place of haphazard reaction, which in chemistry takes place according to the structure of the elements, an animal can adapt its reaction according to circumstances which will serve its own needs, and thus the most important consequence of the nature of the soul as a system of sentient symbols is the possibility of purpose. Man can direct his own course of action according to his foresight and knowledge of the surrounding world and whatever progress has been made and will be made, this will remain true even of the higher man of the future. His dignity and the pride of his superiority will always make it possible for him to pursue a definite purpose. Thereby he can make himself the master of his destiny. 
THE RELIGIOUS ASPECT.

We have explained the origin of the soul in its very beginning, but we have not yet touched upon its nature and significance. Nor can we enter upon this subject to any extent because the field is too large and we would need the full space of another article to do it. But we will here in conclusion at least touch upon the problem, lest our explanation of the lowly origin of the soul and the simple mode of its operation be misunderstood.

There are people who have a misgiving as to the doctrine of evolution because it traces the pedigree of man back to the simians, and even further down to protoplasm and to the very mud of material existence; and their objection is in so far well grounded as man in spite of his kinship to all creation and although he consists of dust, is not born of the dust, but is the child of a higher presence. We have learned that the soul originates in sentiency by the meaning which sensations acquire, and soul is the systematized totality of the meanings which reside in the feelings of an organism. Now let us consider how man's mind is built up from small beginnings, and how he attains that marvelous power which makes him master of the earth and gives him the right to claim divine sonship. The growth of soul is a gradual incarnation of truth. The more correctly and adequately the soul reflects the world, the higher it ranges on the ladder of evolution. Truth is the criterion of the worth of the soul. With the light of reason a new vista is opened to the mind's eye, for a rational being catches glimpses of the universal, the eternal, the divine; it recognizes the vestiges of the cosmic order, of the norms of existence, of God. And so the soul of rational beings is an incarnation of those laws that sway the world; it becomes the dwelling place of the Most High, of the power which dominates the world and guides its course 
with unfailing consistency-humanly speaking, with an absolute wisdom and perfect justice.

It is true that naturalists and psychologists of the present day are apt to overlook the moral significance of the soul, and a protest, such as that made by Mr. F. H. Gile in the present number, seems justified, but we believe that we can (indeed we shall have to) accept all the well assured consequences of science and the scientific conception of the world, of God, and of the soul, all of which appear so negative to the man who still clings to the old faith, or rather to the letter of its dogmas. We accept the scientific solution without, however, falling a prey to moral indifference, and without losing our ideal aspirations. We recognize that the spirit of the old faith is not wrong and wish to preserve all of it that is true and good. As the unity of a man's soul does not depend upon the presence of a monad in his mind, nor of any concrete unit, (be it an atom or a molecule, or a force center), but upon the systematic unification of reason, so our nobility, our dignity and our moral worth are not dependent upon the belief in the traditional conception of the soul as a mysterious entity. On the other hand, when we surrender the letter of a traditional belief, we need not give up the spirit of it; and so we must still preserve our fidelity to that formative factor that so far has guided our advance. We must preserve our love of truth as a divine authority to be respected in its objective import and to be respected even when it might not suit us, and above all we must practically apply our knowledge; we must not only behold and comprehend, but also actualize in our own being, the interrelation of life with life, of soul with soul, the solidarity of the interests of all, and work out our common aim and our common ideals.

People who know and feel the religious character of our moral aspirations, fear that our ideals may be lost when 
the letter of our dogmas passes away, but we have learned that it is not the letter of the old dogmas, it is their spirit which animates all religion and has begotten the dogmas as a transient expression in a bygone period of man's development. For this reason let us listen to the warning of those who find modern psychology, at least as it is commonly taught, sorely wanting in the most essential pointthe moral and religious significance of the soul.

EDITOR. 